\section{TP Periodica Polytechnica Chemical Engineering}

\author{
60(3), pp. 165-168, 2016 \\ DOI: $10.3311 /$ PPch.8260 \\ Creative Commons Attribution (i)
}

RESEARCH ARTICLE

\section{Corrosion Processes Controlled by Phosphonic Acid Nano-layers}

\author{
Talah Abohalkuma ${ }^{1,2}$, Abdul Shaban ${ }^{3}$, Judit Telegdi ${ }^{3,4^{*}}$
}

Received 20 May 2015; accepted after revision 03 October 2015

\begin{abstract}
Self assembled monolayers (SAM) formed by fluorophosphonic and undecenyl-phosphonic acids on carbon steel surfaces as anticorrosive nanocoatings were investigated. The anticorrosive efficacy of these SAM layers was followed by atomic force microscopy, when the change in the surface morphology caused by layer deposition and corrosion processes was monitored. The corrosion process was determined by electrochemical potentiodynamic polarization and cyclic voltammetry. Results showed that both chemicals produced good protection against corrosion as anodic inhibitors specially with increasing the time of layer formation which results in a more compact molecular film. According to the AFM images, the fluoro-phosphonic acid self-assembled molecular layer can control the general as well as the pitting corrosion, but the SAM layers of the undecenyl-phosphonic acid cannot inhibit the pitting corrosion. The AFM measurements confirmed the electrochemical results.
\end{abstract}

\section{Keywords}

corrosion, self-assembled molecular (SAM), phosphonic acid

\section{Introduction}

Self-assembled monolayer (SAM) is one of the new potential alternatives for a metal pre-treatment by ultrathin organic films [1].

This is a flexible method to form thin and well-defined organic coatings for example by hydroxamic and phosphonic acids on a variety of solid surfaces $[2,3]$. The deposition process is simple and inexpensive since the films form spontaneously upon immersion of a solid substrate into a dilute solution of organic adsorbate molecules [4].

Self-assembly requires a relatively strong bond between the substrate and an atom or moiety in the molecule, and an additional lateral interaction among molecules in the monolayer. These monolayers are highly ordered molecular assemblies, formed spontaneously by physi-chemisorptions of the molecule's head group. Once adsorbed onto the surface, these molecules organize themselves through van der Waals interaction among long aliphatic chains [5].

The use of inhibitors is one of the most practical methods for protection against corrosion especially in neutral media. The results presented in numerous publications show that most organic inhibitors form dense films via adsorption on the metal surface [6].

Iron and mild steel corrosion have received a fundamental concern in the academic and industrial research [1]. Due to the low toxicity, high stability, and corrosion inhibitive activity of organic phosphonic acids used in neutral aqueous media, they have become one of the most important and effective chemicals for decreasing the corrosion processes of iron and low alloyed steels. They form strong bonds with several metal oxide substrates mostly through the formation of stable Me-O-P bonds $[7,8]$. The molecular structures of corrosion inhibitors have very important impact on the anticorrosion efficacy as Kuznetsov pointed out in his book [9].

\section{Experimental methods}

\subsection{SAM layers preparation}

Chemicals used for nanolayer preparation were the undecenyl-phosphonic acid (Specific Polymers, SP-61-003) 
and the fluorophosphonic acid (C10) (Specific Polymers, SP-01-003). The organic solvent was methanol (Merck). The solvent and substances were used without further purification. Carbon steel metal samples (composition: C: $2.29 \%$; Fe: $97.71 \%$ ) were grinded with emery paper of different grads (from 200-1200 grit). For AFM measurement, specimen were further polished with diamond past, washed with ethanol and distilled water. Samples were immersed in solutions of fluorophosphonic acid and undecenyl-phosphonic acid for surface films formation. The concentration of each chemical was $5.10^{-3}$ $\mathrm{M}$ and the immersion time ranged from 0.5 up to $48 \mathrm{~h}$.

After the required layer formation time, the samples were pulled out and the superfluous remedy of the solution was removed by dipping the coupons and electrodes into pure solvent and the pre-coated metal samples were dried in air. These coated coupons and electrodes were used for AFM and electrochemical measurements, respectively.

\subsection{Electrochemical measurements}

A three-electrode electrochemical cell of $250 \mathrm{ml}$ volume was used. The electrodes were: saturated calomel electrode (SCE) as the reference, platinum sheet with an area of $7.5 \mathrm{~cm}^{2}$ as the counter electrode, and carbon steel electrode with an area of $1.5 \mathrm{~cm}^{2}$ as the working electrode. For all electrochemical measurements the electrolyte was $0.1 \mathrm{M} \quad \mathrm{NaClO}_{4}$. Potentiodynamic polarization measurements started after the settling of the open circuit potential $\left(\mathrm{E}_{\text {ocp }}\right)$. The measurements were performed with a potential sweep rate of $0.166 \mathrm{mV} / \mathrm{s}$.

\subsection{AFM measurements}

The surface visualization was performed by atomic force microscope (Digital Instruments, NanoScope III). The change in the morphology of carbon steel surface with and without nanocoatings was imaged in contact mode, in air, before and after the corrosive attack. The images are presented as measured, without any modifications.

\section{Results and discussion}

\subsection{Potentiodynamic polarization results}

Figures 1, 2 and 3 summarize the electrochemical results produced by the potentiodynamic measurements. In both cases, in the presence of SAM layers of flouro-phosphonic acid and undecenyl-phosphonic acid, the corrosion current density decreased as the layer formation time increased. The most effective layers were obtained by applying $48 \mathrm{~h}$ coating time. This indicates that there is an improvement in the film structure quality after longer layer formation time which is due to the realignment of molecules in the layer on the solid surface.

At shorter layer formation time $(0.5 \mathrm{~h})$ the inhibition efficiency is almost identical for the two different phosphonic acids, but much smaller than at longer film formation time. At increased immersion times, the differences in the efficiency of the two formed layer reveal themselves. After $4 \mathrm{~h}$, the fluoro-phosphonic acid produces more effective film than the undecenyl phosphonic acid. But long film formation time results in compact films in both cases.

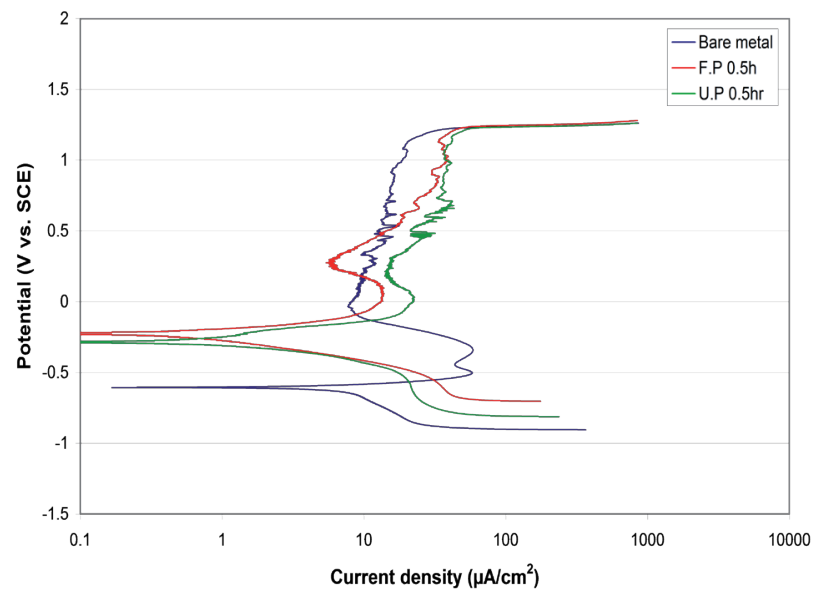

Fig. 1 Potentiodynamic polarization curves for layers formed at $0.5 \mathrm{~h}$ with undecenyl and flouro-phosphonic acids in $\mathrm{NaClO}_{4}$ solution

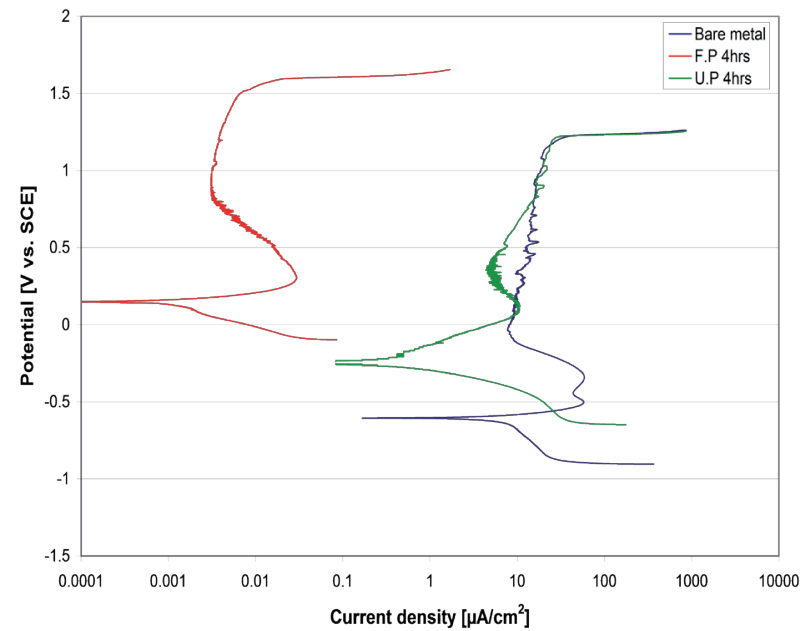

Fig. 2 Potentiodynamic polarization curves for layers formed at $4 \mathrm{~h}$ with undecenyl and flouro-phosphonic acids in $\mathrm{NaClO}_{4}$ solution

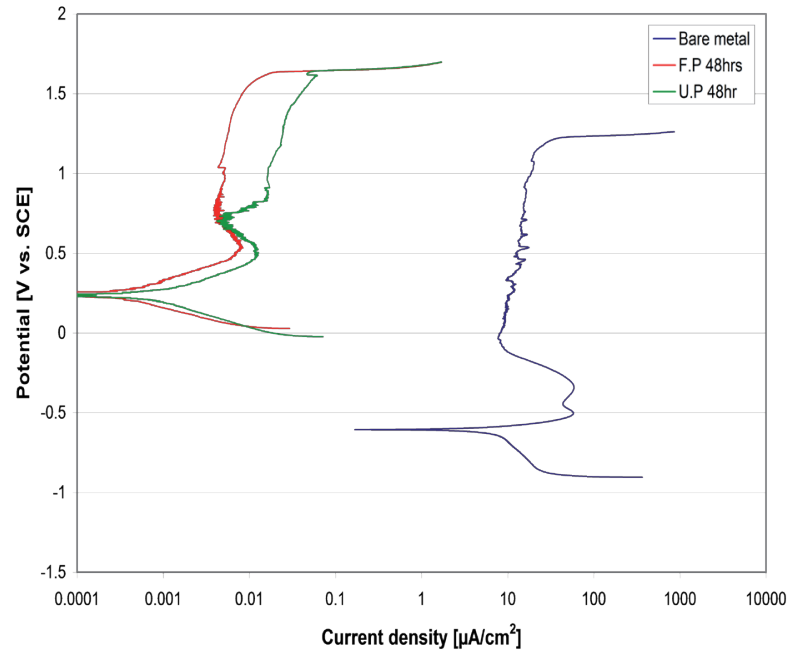

Fig. 3 Potentiodynamic polarization curves for layers formed at $48 \mathrm{~h}$ with undecenyl-phosphonic acid and flouro-phosphonic acids in $\mathrm{NaClO}_{4}$ solution 
Tables 1 and 2 show the electrochemical characteristics of the carbon steel electrode immersed in solutions of $0.1 \mathrm{M} \mathrm{NaClO}_{4}$ without and with the addition of undecenyl-phosphonic acid and flouro-phosphonic acid, for different immersion times. Results of corrosion current density and were obtained using the Tafel extrapolation method performed on Figs. 1-3. The inhibitor efficiency $(\eta)$ of the layers was calculated using Eq. (1).

$$
\eta[\%]=\left(1-\frac{j}{j_{\text {corr }}}\right) 100
$$

Where: $j_{\text {corr }}$ is the current density of the unmodified electrode and $j$ is the current density measured on the coated electrode.

Table 1 Corrosion current density and efficiency values of fluoro-phosphonic acid layers (FP)

\begin{tabular}{llll}
\hline Chemical used & $\begin{array}{l}\text { Time of layer } \\
\text { formation }(\mathrm{h})\end{array}$ & $j_{\text {corr }}\left(\mu \mathrm{A} / \mathrm{cm}^{2}\right)$ & $\eta(\%)$ \\
\hline None & None & 14 & - \\
FP & 0.5 & 3 & 78.6 \\
FP & 48 & 0.12 & 99.1 \\
\hline
\end{tabular}

Table 2 Corrosion current density and efficiency values of undecenyl-phosphonic acid layers (UP)

\begin{tabular}{llll}
\hline Chemical used & $\begin{array}{l}\text { Time of layer } \\
\text { formation }(\mathrm{h})\end{array}$ & $j_{\text {corr }}\left(\mu \mathrm{A} / \mathrm{cm}^{2}\right)$ & $\eta(\%)$ \\
\hline None & None & 14 & - \\
UP & 0.5 & 4 & 71.4 \\
UP & 48 & 0.5 & 96.4 \\
\hline
\end{tabular}

\subsection{AFM results}

The polished carbon steel samples with and without coatings were visualized by AFM after immersion into neutral electrolyte $\left(\mathrm{NaClO}_{4}\right)$ solution in order to visualize the morphological change caused by the aerated aqueous solution as well as into $\mathrm{NaCl}$ solution to study the efficiency of the nanolayers on the pitting corrosion. Images obtained by these experiments represent the surface morphology are shown in Figs. 4 and 5.

Figure $4 \mathrm{a}$ presents the surface of the nanolayer covered mild steel. The lines got at the polishing procedure are visible. Figure $4 \mathrm{~b}$ shows the change in the surface morphology caused by the perchlorate electrolyte in the presence of air. It is clear that the one-hour-long immersion in the perchlorate solution did not cause significant change in the surface morphology. But when the electrolyte contains chloride anions, pits appear on the surface and the possibility given by this technique enables the quantitative scaling of the pit depth. On the other hand, when the coating was built from fluoro-phosphonic acid even the pitting corrosion was inhibited by this nanofilm (Figs. $5 \mathrm{a}, \mathrm{b}$ ).

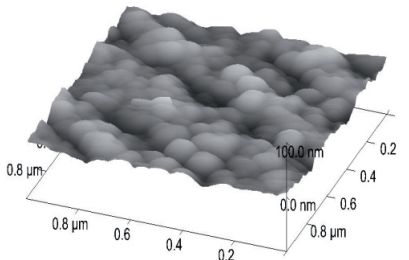

(a)

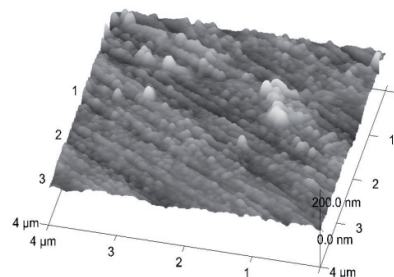

(b)
Fig. 4 Carbon steel surface with undecenyl-phosphonic acid layer (a) and after immersion into perchlorate solution (b)

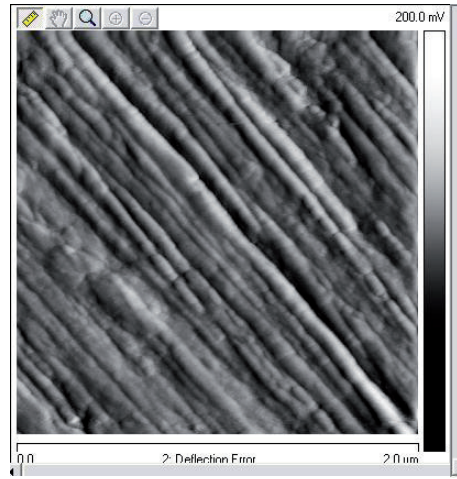

(a)

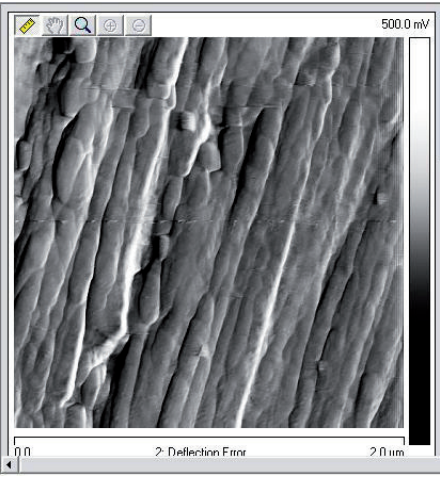

(b)
Fig. 5 Fluorophosphonic acid nanolayer (layer formation time: $0.5 \mathrm{~h}$ ) on carbon steel (a) and after immersion into $\mathrm{NaCl}$ solution (b)

\section{Conclusions}

The focus of this investigation was to investigate two phosphonic acids, fluoro-phosphonic acid and undecenylphosphonic acid, for inhibition characteristics against carbon steel corrosion. Both molecules were applied as self-assembled layers developed on mild steel.

The anticorrosion effectiveness of the coatings was followed by electrochemical techniques. Potentiodynamic polarization measurements made it clear that both nanofilms behave as anodic inhibitor, as the $\mathrm{E}_{\text {corr }}$ is shifted into the anodic potential range and, at the same time, the metal dissolution is hindered significantly which resulted in high corrosion inhibition efficiency. The AFM surface visualization of bare and coated surfaces, before and after immersion in electrolyte, produced valuable information about the effectiveness of the two nanofilms formed on the mild steel surface from the two phosphonic acids. The general and pitting corrosion were inhibited by the fluoro-phosphonic acid films but the undecenyl-phosphonic acid layer effective against general corrosion only. This is the consequence of the material molecular structure. The double bond in the undecenylphosphonic acid molecule does not permit the formation of a compact molecular arrangement in the nanofilm. But this unsaturated bond will permit the modification of the structure of the undecenyl-phosphonic acid film via UV-polymerization which will make the structure of the film denser. 


\section{References}

[1] Felhősi, I., Kálmán, E. "Corrosion protection of iron by $\alpha, \omega$-diphosphonic acid layers." Corrosion Science. 47(3), pp. 695-708. 2005.

DOI: 10.1016/j.corsci.2004.07.007

[2] Rigó, T., Mikó, A., Telegdi, J., Lakatos-Varsányi, M., Shaban, A., Kálmán, E. "Inhibition effect of hydroxamic- and phosphonic acids Langmuir- Blodgett films on iron corrosion in sodium perchlorade solution." Electrochemical and Solid-State Letters. 8(10), pp. B51-B54. 2005. DOI: 10.1149/1.2017947

[3] Alagta, A., Felhősi, I., Bertoti, I., Kálmán, E. "Corrosion protection properties of hydroxamic acid self-assembled monolayer on carbon steel." Corrosion Science. 50(6), pp. 1644-1649. 2008.

DOI: 10.1016/j.corsci.2008.02.008

[4] Jaehne, E., Oberoi, S., Adler, H.-J. P. "Ultra thin layers as new concepts for corrosion inhibition and adhesion promotion." Progress in Organic Coatings. 61(2-4), pp. 211-223. 2008.

DOI: 10.1016/j.porgcoat.2007.09.044

[5] Lam, C. N. C., Wu, R., Li, D., Hair, M. L., Neumann, A. W. "Study of the advancing and receding contact angles: liquid sorption as a cause of contact angle hysteresis." Advances in Colloid and Interface Science. 96(1-3), pp. 169-191. 2002. DOI: 10.1016/S0001-8686(01)00080-X
[6] Amar, H., Benzakour, J., Derja, A., Villemin, D., Moreau, B. "A corrosion inhibition study of iron by phosphonic acids in sodium chloride solution." Journal of Electroanalytical Chemistry. 558, pp. 131139. 2003. DOI: 10.1016/s0022-0728(03)00388-7

[7] Maege, I., Jaehne, E., Henke, A., Adler, H.-J. P., Bram, C., Jung, C., Stratmann, M. "Self-assembling adhesion promoters for corrosion resistant metal polymer interfaces." Progress in Organic Coatings. 34(1-4), pp. 1-12. 1998. DOI: 10.1016/S0300-9440(98)00010-1

[8] Paszternák, A., Felhősi, I., Pászti, Z., Kuzmann, E., Vértes, A., Kálmán, E., Nyikos, L. "Surface analytical characterisation of passive iron surface modified by alkyl- phosphonic acid layers." Electrochimica Acta. 55(3), pp. 804-812. 2010. DOI: 10.1016/j.electacta.2009.09.023

[9] Kuznetsov, Y. I. "Organic inhibitors of corrosion of metals." (Thomas, J. G. N. ed.), Plenum Press, N.Y., London. 1996.

DOI: 10.1007/978-1-4899-1956-4 